Regular article

\title{
Normal range and lateral symmetry in the skin temperature profile of pregnant women
}

\author{
Tânia Pereira ${ }^{a, *}$, Cristina Nogueira-Silva ${ }^{a, b, c}$, Ricardo Simoes ${ }^{\text {d,e }}$ \\ ${ }^{\mathrm{a}}$ Life and Health Sciences Research Institute (ICVS), School of Health Sciences, University of Minho, Campus de Gualtar, $4710-057$ Braga, Portugal \\ ' ICVS/3B's PT Government Associate Laboratory, Braga/Guimarães, Portugal \\ ${ }^{\mathrm{c}}$ Department of Obstetrics and Gynecology, Hospital de Braga, 4710-243 Braga, Portugal \\ d Polytechnic Institute of Cavado and Ave, Campus do IPCA, 4750-810 Barcelos, Portugal \\ ${ }^{\mathrm{e}}$ Institute for Polymers and Composites IPC/I3N, University of Minho, Campus de Azurm, 4800-058 Guimarães, Portugal
}

\section{H I G H L I G H T S}

- This study defines the pattern of skin temperature in the pregnant human body.

- Negative correlation between the BMI and temperature in the pregnant women was verified.

- The age showed strong influence in the skin temperature.

- In normal pregnant subjects the skin temperature is symmetrically distributed.

- Thermography could represent an important tool for diagnosis in the gestational period.

\section{A R T I C L E I N F O}

\section{Article history:}

Received 9 May 2016

Revised 21 July 2016

Accepted 21 July 2016

Available online 22 July 2016

\section{Keywords:}

Pregnancy

Thermal imaging

Medical thermography

Skin temperature

Age

Body mass index

\begin{abstract}
A B S T R A C T
Body skin temperature is a useful parameter for diagnosing diseases and infrared thermography can be a powerful tool in providing important information to detect body temperature changes in a noninvasive way. The aim of this work was to study the pattern of skin temperature during pregnancy, to establish skin temperature reference values and to find correlations between these and the pregnant population characteristics. Sixty-one healthy pregnant women (mean age $30.6 \pm 5.1$ years) in the 8th-40th gestational week with normal pregnancies were examined in 31 regions of interest (ROI). The ROIs were defined all over the body in order to determine the most influenced by factors such as age or body mass index (BMI). The results obtained in this work highlight that in normal pregnant women the skin temperature is symmetrically distributed, with the symmetrical areas differing less than $0.5^{\circ} \mathrm{C}$, with a mean value of $0.25 \pm 0.23^{\circ} \mathrm{C}$. This study identified a significant negative correlation between the BMI and temperature. Age has been shown to have great influence on the skin temperature, with a significant increase of temperature observed with age. This work explores a novel medical application of infrared thermography and provides a characterization of thermal skin profile in human pregnancy for a large set of ROIs while also evaluating the effects of age and BMI.
\end{abstract}

(c) 2016 Elsevier B.V. All rights reserved.

\section{Introduction}

The skin temperature of the human body is an important physiological parameter and an accessible and useful measurement for investigating some aspects of peripheral circulation, thermoregulation and structural changes in several diseases that causes localized increases in temperature, which show as hot spots or as asymmetrical patterns in skin temperature [1-3].

\footnotetext{
* Corresponding author.

E-mail addresses: taniapereira@ecsaude.uminho.pt, taniapereira10@gmail.com (T. Pereira).
}

Thermography has several important features for medical measurements, such as noninvasive, non-contact, reliable, capable of producing multiple recordings at short time intervals, and safe for patients and clinicians [3,4]. Moreover, advances in infrared detectors (better temperature sensitivity and spatial resolution) boosted the use of this technology in medical applications and it is becoming an accurate medical diagnostic tool for abnormal temperature pattern measurements [5].

Infrared thermography has been successfully used in diagnosis of several diseases and proved as a useful tool to access important information that may help in disease diagnosis and monitoring the 
therapeutic effect and the evolution of pathologic conditions $[3,6]$. The visualization of temperature distribution on the surface of the human body can provide valuable diagnostic information, and is mostly a reflection of the processes inside the body [7-9]. Altered temperature is often the first sign of tissue lesions, before structural or functional changes can be observed $[7,10]$. Abnormalities such as inflammation and infection cause localized increases in temperature $[6,11]$. Differences in the surface temperature were verified in breast cancer, with higher values in malignant breast than in normal ones [8]. The use of thermography was referred as an important tool for preliminary screening procedure in asymptomatic women to pin-point those with high risk of breast cancer [12]. The asymmetry in the temperature between corresponding sites of the left and right foot is an early warning sign of foot disease in diabetes [13-15]. In the Raynauds phenomenon, thermography provides useful information to quantify the damage, the time evolution of the disease, and to assess recovery after the treatment [5]. In rheumatoid arthritis, thermography was used to identified the abnormal temperature distributions over joints and to evaluate the therapeutic efficacy of different treatment approaches $[3,5,16]$. In plastic and reconstructive surgery, thermography allows to identify dominant vessels before flap surgery, and to monitor the perfusion after connecting its vessels (artery and vein) to the site of reconstruction [16]. Thermal research of skin temperature on human athletes allows screening individuals sports injuries and exercise-induced physiological functions [17]. The efficacy of therapeutic drugs that can change the blood flow through the skin vessels and alter the heat radiation of the skin surface can be studied and monitored using thermography [18,7].

Thermal information have been used to quantify changes in skin temperature in relation to certain diseases or features of the subject such as the age or body mass index [19,9]. Studies on the effect of the BMI in core temperature have shown that core temperature varies inversely to the BMI value [19-22]. In the specific region of the abdominal area skin temperature was found to be significantly lower in obese subjects than in normal BMI subjects $[19,21]$. The study also empathizes the need of future work that evaluates the temperature in more regions of interest [21]. The skin temperature was not extensively studied with age-related changes. However, in the upper regions of the body, skin temperatures in aged people are higher than in young individuals [23].

Pregnancy represents a period characterized by numerous changes in the body and might be associated with several diseases, such as hypertension or venous insufficiency [24]. Biomedical research aims to continuously improve diagnostic devices and to develop new ones for less invasive monitoring. Despite infrared thermography having been applied with important results in several fields of medicine, their use in obstetrics remains unexplored. Thermography could become an important tool for diagnosis in the gestational period since it allows the identification of asymmetry and detection of abnormal temperatures for the specific regions. It might even have applications in examination of local anomalies in outpatients, or monitoring during labor. Therefore, it is extremely relevant to investigate in more detail the thermal profiles associated with pregnancy. This study is a followup of preliminary work developed with pregnant women during in the late gestational period, on 10 ROIs [24]. The present paper presents an extensive study of body temperatures that explores 31 ROIs in the anterior, posterior and lateral views of human body in 61 pregnant woman within a wide range of gestation. The correlation of skin temperature and physiological characteristics were evaluated in order to define the areas most influenced by age, BMI and gestational age. Our main aim was to establish skin temperature reference values for pregnant females, a descriptive work never before reported. Although we did not have the possibility to include also a control group of non-pregnant subjects in this study, we hope this will be possible in the future. Nevertheless, the agreement between the results obtained in this work and the main results obtained in the studies with non-pregnant healthy women, referred in most recently studies, were verified and discussed.

\section{Materials and methods}

The study protocol was approved by the ethical committee of the Braga Hospital, Portugal. All the subjects were volunteers and gave a written informed consent before participation in the study. All volunteers consented to have their vital signals and thermal body image collected as well as information regarding age, gestational age and BMI. They were recruited at the time of their regular obstetrics appointment at the Department of Obstetrics.

\subsection{Study group}

The group consisted of 61 pregnant women at different gestational age (between 8 and 40 weeks). All subjects were considered clinically healthy individuals and undergoing a normal pregnancy. The characteristics of the volunteers are presented in Table 1.

According to World Health Organization [25], the BMI is defined in five categories. The BMI classification used in this study is a generalist classification; however, the objective was to study the effect of spectrum of weight ranks in the mean temperature; for this reason the BMI classification was used in order to stratify the population with different weights. The underweight $\left(\leqslant 18.5 \mathrm{~kg} / \mathrm{m}^{2}\right), 1$ subject in the moment of their thermography images were captured with 34 years old and 10 pregnancy weeks; normal weight $\left(18.5-24.9 \mathrm{~kg} / \mathrm{m}^{2}\right)$ was characterized by $32.6 \pm 4.0$ years old and $22.5 \pm 12.2$ pregnancy weeks; overweight $\left(25-29.9 \mathrm{~kg} / \mathrm{m}^{2}\right)$ with $32.0 \pm 4.4$ years old and $31.0 \pm 10.8$ pregnancy weeks; obese type $1\left(30-34.9 \mathrm{~kg} / \mathrm{m}^{2}\right)$ with $27 \pm 5.4$ years old and $37.0 \pm 1.7$ pregnancy weeks; and in the last category considered obese type 2 ( $\geqslant 35 \mathrm{~kg} /$ $\mathrm{m}^{2}$ ) was characterized by $28 \pm 6.7$ years old and $37.0 \pm 2.9$ pregnancy weeks. The values for the BMI were determined for the moment of the data was acquired, which means that could be an effect from the advancement of pregnancy and not only an obesity process.

Focusing on the analysis of the population based in pregnancy quarter category, the study group with a gestation time until 12 weeks ( $9.9 \pm 1$ pregnancy weeks), with 10 subjects, had a mean age of $33.1 \pm 4.3$ years old, and a value of $23.2 \pm 3.2 \mathrm{~kg} / \mathrm{m}^{2}$ for the BMI. The group with gestation time between the 13 to 24 $(16.2 \pm 3.8$ pregnancy weeks), composed by 11 subjects, was characterized by $30.5 \pm 4.4$ years old and with a BMI of $23.2 \pm 2.5 \mathrm{~kg} /$ $\mathrm{m}^{2}$. The study group in the last trimester $(36.7 \pm 2.3$ pregnancy weeks), composed by 45 subjects, had a mean age of $30.0 \pm 5.3$ with a BMI of $29.3 \pm 4.7 \mathrm{~kg} / \mathrm{m}^{2}$.

The three categories defined by age were composed by 26 pregnant women 30 years (mean age of $26 \pm 3.1$ years old), and with a gestation time of $30 \pm 11$ pregnancy weeks, and $30 \pm 5.4 \mathrm{~kg} / \mathrm{m}^{2}$ BMI. The group with age between 30 to 39 years old ( $34 \pm 2.4$ years) was composed by 34 subjects with a mean $28 \pm 11.9$ pregnancy week, and $26 \pm 4.6 \mathrm{~kg} / \mathrm{m}^{2} \mathrm{BMI}$. The last group, subjects with more than 40 years, was composed by 2 subjects

Table 1

Main characteristics of the studied group.

\begin{tabular}{ll}
\hline Characteristics $(n=61)$ & Mean \pm SD \\
\hline Age, years & $30.6 \pm 5.1$ \\
Gestational age, weeks & $29.3 \pm 11.5$ \\
BMI $\left(\mathrm{kg} / \mathrm{m}^{2}\right)$ & $27.5 \pm 5.1$ \\
\hline
\end{tabular}


with 41 years old, in the $16 \pm 7.8$ pregnancy weeks, and $23 \pm 0.8 \mathrm{~kg}$ / $\mathrm{m}^{2} \mathrm{BMI}$.

\subsection{Methods}

The FLIR SC640 (thermal) infrared camera with a resolution of $640 \times 480$ pixels, a measurement accuracy (bias, offset) of $2{ }^{\circ} \mathrm{C}$ and a resolution of $0.1^{\circ} \mathrm{C}$ was used to capture the thermal images. For all tests, the camera was fixed to a rigid tripod to assure stability of camera angle and positioning, and turned on for at least $30 \mathrm{~min}$ in order to reach thermal equilibrium with the environment and the operators, before any measurements were taken. The emissivity was setup for the skin value of 0.98 . All thermal profiles were registered as single images.

The quality assurance method to ensure traceability of the temperature measurements involved the usage of a black body LANDs $\mathrm{P}$ 80P as temperature reference traceable to the internationally accepted temperature scale of ITS-90, with the internal temperature set to $30^{\circ} \mathrm{C}$. An image was taken from it before a subject investigation and other immediately after, both images were compared and if there was a difference superior to $0.1^{\circ} \mathrm{C}$ in the mean temperature of the reference ROI (a circle around the center with $5 \mathrm{~cm}$ diameter), the whole set of images was not considered for this study.

Measurements were performed at the Hospital of Braga, Portugal. All the subjects on this study had refrained from having a heavy meal, smoking, drinking or using drugs earlier on the day of the examination. None of them used oil or any ointments, practiced sports, or had physiotherapy on that day either. For acclimatization, subjects were in the room for at least $15 \mathrm{~min}$ before measurements. They were requested to strip and remove any object that could interfere with the experiments. The sampling room had a temperature-controlled environment, and was permanently kept at $20^{\circ} \mathrm{C}$ [26]. Each exam procedure consisted in the acquisition of a set of thermal images from different views of the human body. The camera remained stationary, and the subject was requested to rotate by $90^{\circ}$ for each subsequent image, that allows to collected the profile images for each perspective quadrant (anterior, left, posterior, and right). Thermal images were recorded with the subjects standing in front of a white wall. All collected data were analyzed with the software package provided with the thermal camera, Therma CAM Researcher Professional 2.8 SR-2.

\subsection{Regions of interest}

The temperature images of different parts of the human body were extensively studied. A total of 31 ROIs were selected and defined all over the body in order to determine the correlation with the factors such as the age or body mass index [27].

Different studies use different areas of human body [22,4]. The definition of ROI remains a great challenge to accurately determine the boundary of a region of interest in a consistent and unambiguous manner. Ring et al., refers to the same number of pixels as a condition to fix the distance of the subject from the camera [27]. However, while constant pixel count is possible for some localized studies, it is not easily done for the entire human body. The regions of interest used in the study were defined by the clinicians that participated in the study, trying to cover all the body, with focus in the areas where more changes during the pregnancy were expected [4]. The selected areas correspond to the body areas with as much information as possible, and simultaneously, are areas with a high degree of reproducibility by the clinicians in the measurements [27]. For this purpose, geometrically regular shapes were used in order to decrease the subjective effect in the ROI definition. The regular shape was selected trying to overlap the body surface in study and anatomical features were used to locate the extremities of the shape.

The profile images were collected for each perspective quadrant (anterior, left, posterior, and right) in order to wide analysis of the human body. For the anterior profiles, 12 ROI were defined (Fig. 1 (a)), with Ax-left and Ax-right concerning the axilla zone, and $\mathrm{C}$ to the chest zone, the A1-left and A1-right concerning the breasts, the A2-left and A2-right concerning the upper abdomen, and the A3left and A3-right concerning the lower abdomen. The A1 ROI was centered as much as possible on the nipple, and kept with the limit of the breast; the A2 ROI above the umbilical region and extending vertically to the end of the upper abdomen; the A3 ROI at tempts to capture the shape of the rest of the belly and $\mathrm{D}$ the pelvic area. Also in the front view were defined face areas, F-left and F-right at the cheeks and FH at the forehead. The UFL-left and UFL-right concern the upper legs and DFL-left and DFL-right the lower zone of the legs.

In the posterior profiles presented in Fig. 1(b), 10 ROI were defined, namely P1-left and P1-right concerning the upper back region, and also P2-left and P2-right concerning the lumbar region, $\mathrm{N}$-left and N-right regarding the buttocks zone, and UBL-left and UBL-right the upper zone in the legs and DBL-left and DBL-right the lower zone. For the lateral profiles were analyzed four regions (Fig. 2), B-left and B-right concerning the belly, and LI-left and LIright concerning the inside area of the legs.

\subsection{Statistical analysis}

Data is reported as mean \pm standard deviation, within $95 \%$ confidence intervals. Intraclass correlation coefficient was computed for repeatability studies, based on one-way analysis of variance (ANOVA). Cronbach's alpha was used as a measure of internal consistency, that is how closely related ROIs values are as a group. The Pearson correlation was used to study the correlation between the temperature and features of population. Statistical analysis was performed by SPSS software, version 22.0 (SPSS Inc., Chicago, Illinois).

\section{Results}

The mean temperature value and standard deviation for each ROI for all subjects is presented in Fig. 3. The highest average mean temperature was observed in the anterior view at the Ax ROI. In the posterior view, the higher mean was Pi ROI, in the lateral view was the B ROI and in the face was the FH. The global lowest average mean temperature was at the N ROI.

In a global analysis of the temperature patterns, it is possible to identify the perspective (posterior, anterior, lateral and face in Fig. 3) with higher temperature values. In particular the ROIs of the face present the highest mean temperature with $34.9 \pm 1.1^{\circ} \mathrm{C}$. The anterior ROIs present mean values of $33.9 \pm 1.7^{\circ} \mathrm{C}$, the posterior ROIs a mean value of $32.6 \pm 1.7^{\circ} \mathrm{C}$ and the lateral ROIs of $33.7 \pm 1.4{ }^{\circ} \mathrm{C}$. The differences between the mean values and the regions represents a significant correlation of 0.358 of Pearson correlation coefficient (significant at the 0.01 level (2-tailed)). The LI areas are in contact of the left and right limb (touching, rubbing) and for this reason the values for the temperature obtained are an average of temperature in this zone. In spite of that subjects were stationary for some minutes before the measurements, minimizing the amount of rubbing between limbs.

The similarity between the left and right areas for each ROI is evidenced Fig. 4, where the temperature measured in left and respective right ROI was represented side by side. Fig. 4 also represents the distribution of measurements and the respective normal 


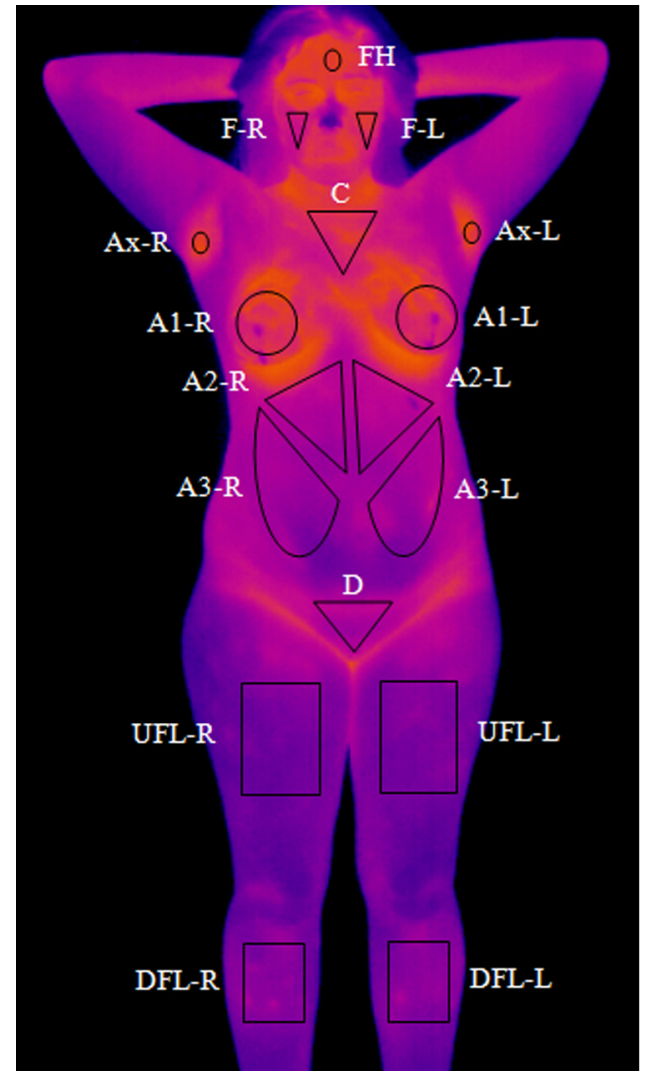

(a) Anterior regions.

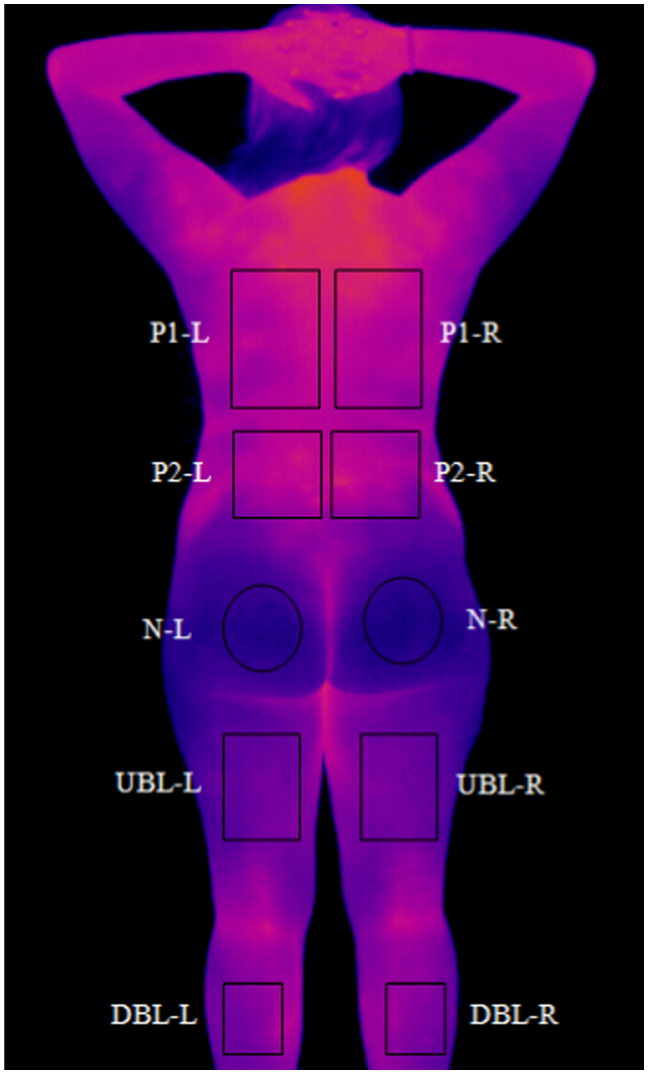

(b) Posterior regions.

Fig. 1. Definition of the anterior and posterior ROIs.

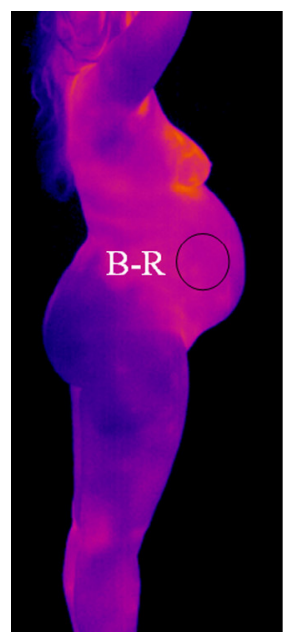

(a) ROI of belly.
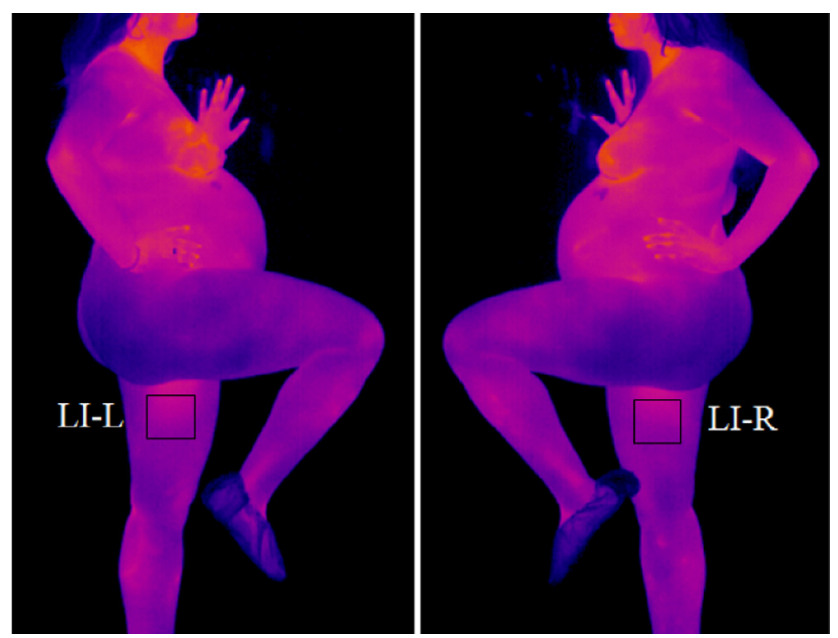

(b) ROI of leg.

Fig. 2. Definition of the lateral ROIs.

curve to the histogram and reveals the symmetry values per ROI by the similar shapes of the distribution on left and right side. The ROI that presented the highest variation in temperature distribution was A1.

Two statistical tests were used to assure data consistency (Reliability Coefficient Alpha or Cronbachs alpha coefficient) and repeatability (Inter-Class Correlation and Coefficient with 95\% i.c. interval) in the ROI measurements. In order to run those tests, the captured images were analyzed and similar ROIs in that analysis by two experienced researchers in the same set of images that was used as input for the previously outlined statistical tests. The considered set in the results was the set that presented the best thermal symmetry values. Results for the coefficients are shown in Table 2 and all are above 0.90 . Thus, ROI are repeatable and the data measured has statistical evidence of being internally consistent. 


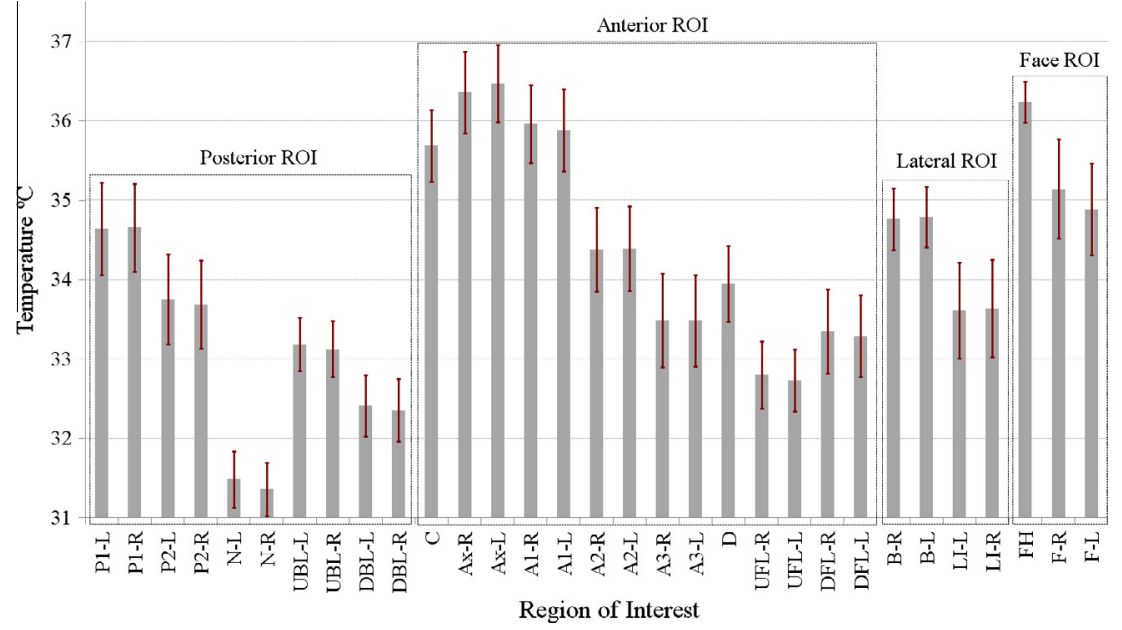

Fig. 3. Average mean temperatures with respective standard deviations per ROI.

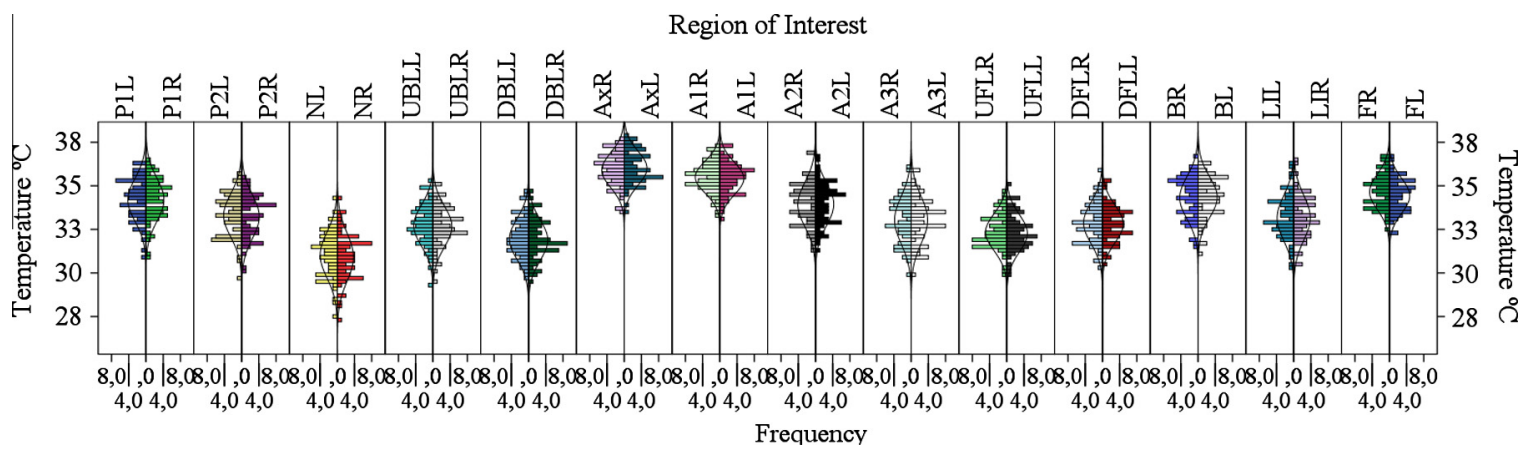

Fig. 4. Distribution of thermal symmetry values per ROI.

Table 2

Statistics for the repeatability and data consistency for the different ROIs.

\begin{tabular}{|c|c|c|c|c|c|c|c|c|c|c|c|c|c|c|}
\hline ROI & P1 & P2 & $\mathrm{N}$ & UBL & DBL & $A x$ & A1 & A2 & A3 & UFL & DFL & B & LI & $\mathrm{F}$ \\
\hline $\begin{array}{l}\text { Reliability } \\
\text { Coeff }\end{array}$ & 0.99 & 0.99 & 0.99 & 0.98 & 0.97 & 0.94 & 0.97 & 0.99 & 0.99 & 0.98 & 0.97 & 0.98 & 0.99 & 0.95 \\
\hline ICC & 0.98 & 0.98 & 0.98 & 0.97 & 0.94 & 0.90 & 0.96 & 0.99 & 0.98 & 0.96 & 0.95 & 0.97 & 0.98 & 0.88 \\
\hline $\begin{array}{l}95 \% \text { of } \\
\text { Conf }\end{array}$ & $\begin{array}{l}0.96- \\
0.99\end{array}$ & $\begin{array}{l}0.96- \\
0.99\end{array}$ & $\begin{array}{l}0.96- \\
0.98\end{array}$ & $\begin{array}{l}0.94- \\
0.98\end{array}$ & $\begin{array}{l}0.91- \\
0.96\end{array}$ & $\begin{array}{l}0.83- \\
0.93\end{array}$ & $\begin{array}{l}0.92- \\
0.97\end{array}$ & $\begin{array}{l}0.98- \\
0.99\end{array}$ & $\begin{array}{l}0.97- \\
0.99\end{array}$ & $\begin{array}{l}0.92- \\
0.97\end{array}$ & $\begin{array}{l}0.91- \\
0.96\end{array}$ & $\begin{array}{l}0.94- \\
0.98\end{array}$ & $\begin{array}{l}0.97- \\
0.99\end{array}$ & $\begin{array}{l}0.84- \\
0.94\end{array}$ \\
\hline
\end{tabular}

Reliability Coeff - Reliability Coefficient Alpha.

ICC - Inter-Class Correlation Coefficient.

95\% of Conf - 95\% of Confidence Interval (upper and lower limits).

The values of thermal symmetry were calculated performing an absolute difference between the left and right ROI across the longitudinal human body main axis. The obtained results are presented in Fig. 5. The regions with higher differences between left and right side are the armpit and the face, likely due to the small area that is analyzed. However, for all ROIs the differences between sides are very small, always less than $0.4^{\circ} \mathrm{C}$. The maximum value obtained was of $0.4 \pm 0.2{ }^{\circ} \mathrm{C}$ for the $\mathrm{F}$ ROI and the minimal was of $0.2 \pm 0.1^{\circ} \mathrm{C}$ for the A2 ROI.

\subsection{Age influence}

The population under study was categorized in three groups: under 29 years, 30-39 years and $40-50$ years old. From Fig. 6 an increase of temperature is evident for all ROIs with the age of the pregnant woman.

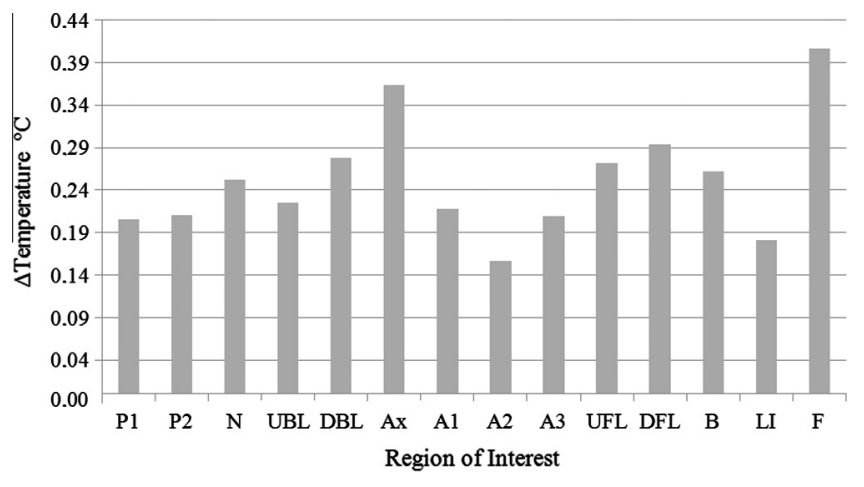

Fig. 5. Thermal symmetry values per ROI. 


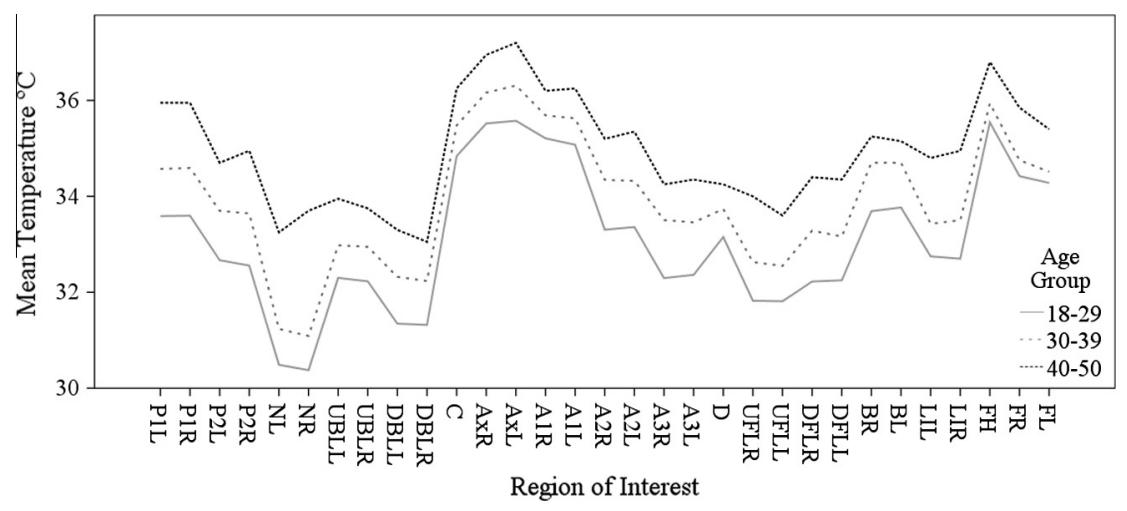

Fig. 6. Thermal mean values per ROI for different age groups.

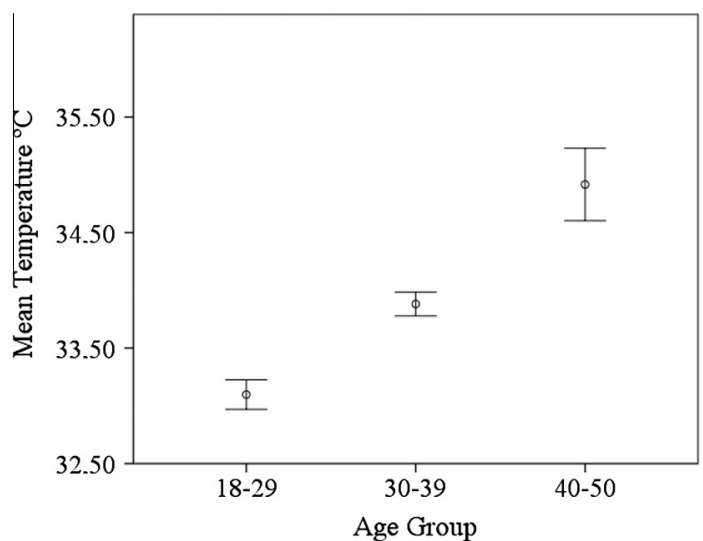

Fig. 7. Mean temperature values per age group. Error bars indicate the $95 \%$ confidence interval of the sample mean.

Different mean values for the measured temperature were found according to the age group, with a slight increase with age (Fig. 7). The 18-29 age group presents a mean temperature of $33.1 \pm 1.8^{\circ} \mathrm{C}$, the $30-39$ group a mean of $33.9 \pm 1.7^{\circ} \mathrm{C}$, and the 40-50 group a mean of $34.9 \pm 1.2{ }^{\circ} \mathrm{C}$.

The Pearson correlation analysis shows a moderate correlation of 0.325 (significant at the 0.01 level (2-tailed)) between age and temperature. This correlation was studied for the individual ROI. The regions in analysis that present the higher correlations were: P1, P2, DBL, C, A2, A3, UFL, DBL, B and LI. All these regions present a Pearson coefficient above 0.5 . The region DFL presents the largest value, circa 0.7 .

\subsection{BMI influence}

The average measured temperature values per BMI class are shown in Fig. 8. The average mean temperatures were significantly lower with weak positive correlation in the women with higher body mass (Pearson correlation of 0.184 , significant at the 0.01 level (2-tailed)), where the influence of the BMI, would be expected due to the effect of fat mass on the human body thermoregulation. This study verified the significant negative Pearson Correlation between the BMI and temperature, which is in agreement with the literature references $[20,28]$. The BMI of women during pregnancy is expected higher with the increase of weight during the gestation.

\section{Discussion}

This study has revealed the patterns of thermal values for a wide range of ROIs in the pregnant human body. The upper regions

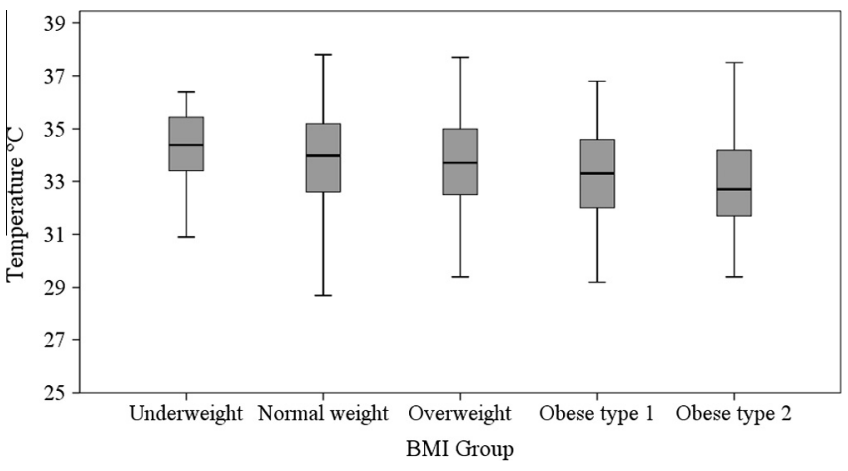

Fig. 8. Box plot of data from the temperature Vs BMI categories.

of the pregnant human body presents higher values of temperature, namely the chest, axilla, breasts and face. The regions with lower mean temperature values are located on the legs. This distribution of temperature values is in agreement with other studies indicating that the temperature of the skin covering the extremities is lower than of the skin covering the head and the torso $[19,22,29,24,30]$.

The results obtained in this work highlight the fact that in healthy subjects the skin temperature is symmetrically distributed $[19,5]$. Symmetrical areas differ less than $0.5^{\circ} \mathrm{C}$, with the mean value for the difference between the skin's temperature on the lateral body sides $\left(0.25 \pm 0.23^{\circ} \mathrm{C}\right)$ in the expected range for nonpregnant subjects $[9,29,31]$. Thermal symmetry found in healthy pregnant subjects increases the expectation that symmetry variance could be of significant value in the assessment of disorders that unilaterally manifest affecting thermal features on the human skin in pregnant women. For instance, abnormal muscle strain, excessive lumbar lordosis or nerve entrapment, are painful and common problems occurring during pregnancy. In fact, thermography might be of significant value in the assessment of musculoskeletal or neurological disorders that manifest by changes in normal thermal symmetry. Moreover, after description of thermal pattern in normal pregnant women, it would be very interesting to study possible thermal irregularities induced by common pathologies of pregnancy, such as urinary infections, gestational hypertensive disease or placental insufficiency. This could allow to assess the true usefulness of thermography in the obstetric clinical setting.

A moderate correlation was found for the skin temperature and the age of pregnant woman. The two groups with lower age (less than 30 and 30 to 40 years old) are homogeneous for other features, as pregnancy week and BMI, suggesting that these features have no contribution for the differences in the temperature between the group ages. 
Previous human studies showed that obesity causes a decrease in the metabolic rate, and a decrease in core body temperature [28]. It is expected that there is a significant inverse correlation between body mass and mean body temperature, suggesting that body mass is a factor in determining mean body temperature $[20,22,19,28]$. This study confirmed that the inverse correlation between BMI and skin temperature is also verified during pregnancy.

The groups split by the gestation time were characterized and used to correlate with the temperature profile; however, a weak correlation was found (Pearson correlation of -0.077 , significant at the 0.01 level, 2-tailed). The groups are homogenous for the age not having the contribution of this variable on the temperature differences. The last trimester group shows an expected increase of BMI. The BMI shows a negative correlation with mean temperature, which indicates that increase of pregnancy week and the consequent increase of weight results in a decrease of mean temperature. The weak correlation between temperature profile and gestation time interval might be due to the most significant changes, such as the vascularization of the breast and belly to prepare the woman body for pregnancy, occurring in the beginning of the gestation period. To clarify this issue and provide a better understanding of the effect of pregnancy week on the temperature distribution in pregnant women, a more detailed study will be required.

\section{Conclusion}

The aim of this study was to achieve a better understanding of skin profile temperature during pregnancy in healthy human females, which corresponds to a phase with a wide range of biological changes, many of which influence skin temperature. This work highlights the fact that in healthy subjects the skin temperature is symmetrically distributed, even in the pregnancy phase, with the symmetrical areas differing less than $0.5^{\circ} \mathrm{C}$. The studies of temperature with biological features of pregnant woman reveal some important correlations. A significant negative correlation between BMI and temperature was identified, and also between pregnancy week and temperature. Moreover, a significant increase of temperature with age was observed. This study represents an important (and previously inexistent) contribution to define reference values for the global areas of skin temperature along human pregnancy. A non-invasive thermal diagnostic tool that uses the infrared thermal image of skin surface and accurate correlations to the human pathophysiology could represent an important method to detect some pathological alterations during the pregnancy. Future work will consider the comparison between pregnant and nonpregnant females in order to identify the relevant differences in the skin temperature occurring with gestation. Major changes are expected to be occur at the level of the muscles of the back and chest to sustaining the increased uterus and fetus, and the vascularization of the mammary area due to the changes taking place in the mammary glands [32]. These changes were not identified in this study, possibly because they occur in the very early stages of pregnancy, a fact that must be pursued further and clarified in more detail in subsequent research.

\section{Acknowledgments}

This work is funded by FEDER funds through the COMPETE 2020 Programme and National Funds through FCT - Portuguese Foundation for Science and Technology under the project UID/CTM/50025/2013. Thermal equipment provided through the REEQ/ 1033/CTM/ 2005 POCI 2010 program. Project "Do-IT", co-financed by the European Community Fund through
COMPETEPrograma Operacional Factores de Competitividade. Hospital de Braga for authorizing the study and providing facilities for data collection. We also acknowledge the collaboration from the entire staff at the Department of Obstetrics and Gynecology of the Hospital de Braga.

\section{References}

[1] V. Kotrbáček, H.-R. Nau, The changes in skin temperatures of periparturien sows, Acta Veterinaria Brno 54 (1985) 35-40.

[2] A. Helmy, M. Holdmann, M. Rizkalla, Application of thermography for noninvasive diagnosis of thyroid gland disease, IEEE Trans. Biomed. Eng. 55 (2008) 1168-1175.

[3] S. Bagavathiappan, T. Saravanan, J. Philip, T. Jayakumar, B. Raj, R. Karunanithi, T. Panicker, M.P. Korath, K. Jagadeesan, Infrared thermal imaging for detection of peripheral vascular disorders, J. Med. Phys. 34 (2009) 43-47.

[4] N. Ludwig, D. Formenti, M. Gargano, G. Alberti, Skin temperature evaluation by infrared thermography: comparison of image analysis methods, Infrared Phys. Technol. 62 (2014) 1-6.

[5] B. Lahiri, S. Bagavathiappan, T. Jayakumar, J. Philip, Medical applications of infrared thermography: a review, Infrared Phys. Technol. 55 (2012) 221-235.

[6] D. Rallan, C.C. Harland, Skin imaging: is it clinically useful?, Clin Exp. Dermatol. 29 (2004) 453-459.

[7] L. Jiang, E. Ng, A.C.B. Yeob, S. Wua, F. Pana, W.Y. Yaua, J.H. Chenb, Y. Yangb, A perspective on medical infrared imaging, J. Med. Eng. Technol. 29 (2005) 257267.

[8] N.M. Sudharsan, E.Y.K. NG, S.L. Teh, Surface temperature distribution of a breast with and without tumour, Comput. Meth. Biomech. Biomed. Eng. 2 (1999) 187-199.

[9] M. Chudecka, Use of thermal imaging in the evaluation of body surface temperature in various physiological states in patients with different body compositions and varying levels of physical activity, Cent. Eur. J. Sport Sci. Med. 2 (2013) 15-20.

[10] J. Liu, Y.-x. Zhou, Z.-S. Deng, Temperature sensor array system for thermal diagnostics on human disease, in: 23rd Annual Conference IEEE/EMBS Oct.2528, 2001, Istanbul, Turkey, 2001, pp. 3188-3191.

[11] H. Peregrina-Barreto, L.a. Morales-Hernandez, J.J. Rangel-Magdaleno, J.G. Avina-Cervantes, J.M. Ramirez-Cortes, R. Morales-Caporal, Quantitative estimation of temperature variations in plantar angiosomes: a study case for diabetic foot, Comput. Math. Meth. Med. 2014 (2014).

[12] H.J. Isard, W. Becker, R. Shilo, B.J. Ostrum, Breast thermography and after four years and 10,000 studies, Am. J. Roentgenol. Radium Ther. Nucl. Med. 115 (1972) 811-821.

[13] D.G. Armstrong, L.A. Lavery, Monitoring neuropathic ulcer healing with infrared dermal thermometry, J. Foot Ankle Surg. 35 (1996) 335-338.

[14] A. Skafjeld, M.M. Iversen, I. Holme, L. Ribu, K. Hvaal, B.K. Kilhovd, A pilot study testing the feasibility of skin temperature monitoring to reduce recurrent foot ulcers in patients with diabetes a randomized controlled trial, BMC Endocr. Disorders 15 (2015) 55.

[15] D.G. Armstrong, K. Holtz-Neiderer, C. Wendel, M.J. Mohler, H.R. Kimbriel, L.A. Lavery, Skin temperature monitoring reduces the risk for diabetic foot ulceration in high-risk patients, Am. J. Med. 120 (2007) 1042-1046.

[16] L. Vilcahuaman, Early diagnosis of diabetic foot using thermal images (Ph.D. thesis), Universite d'Orleans, 2013.

[17] C. Hildebrandt, K. Zeilberger, E. Ring, C. Raschner, The application of medical infrared thermography in sports medicine, An International Perspective on Topics in Sports Medicine and Sports Injury Edited, vol. 14, InTech, 2012, pp. $257-275$.

[18] G. Stuttgen, Thermographic evaluation of the benign diseases and reactive changes of the skin, Prog. Clin. Biol. Res. 107 (1982) 397-411.

[19] M. Chudecka, A. Lubkowska, Thermal maps of young women and men, Infrared Phys. Technol. 69 (2015) 81-87.

[20] K. Adam, Human body temperature is inversely correlated with body mass Eur. J. Appl. Physiol. 58 (1989) 471-475.

[21] D.M. Savastano, A.M. Gorbach, H.S. Eden, S.M. Brady, J.C. Reynolds, J.a. Yanovski, Adiposity and human regional body temperature, Am. J. Clin. Nutr. 90 (2009) 1124-1131.

[22] M. Chudecka, A. Lubkowska, A. Kempińska-Podhorodecka, Body surface temperature distribution in relation to body composition in obese women, J Therm. Biol. 43 (2014) 1-6.

[23] M.A. Farage, Textbook of Aging Skin, Springer, Berlin, Heidelberg, 2010.

[24] R. Simoes, R. Vardasca, C. Nogueira-Silva, Thermal skin reference values in healthy late pregnancy, J. Therm. Biol. 37 (2012) 608-614.

[25] World Health Organization Expert Committe on Physical Status, Physical Status: the Use and Interpretation of Anthropometry, Report of a WHO Expert Committee. Technical Report Series No. 854, 1995.

[26] E. Ring, K. Ammer, The technique of infrared imaging in medicine, Thermol Int. 10 (2000) 7-14.

[27] E. Ring, K. Ammer, A. Jung, P. Murawski, B. Wiecek, J. Zuber, S. Zwolenik, P. Plassmann, C. Jones, B.F. Jones, Standardization of infrared imaging, in: Conference Proceedings: Annual International Conference of the IEEE Engineering in Medicine and Biology Society, Annual Conference, vol. 2, IEEE Engineering in Medicine and Biology Society, 2004, pp. 1183-1185. 
[28] M.J. Heikens, A.M. Gorbach, H.S. Eden, D.M. Savastano, K.Y. Chen, M.C. Skarulis, J.a. Yanovski, Core body temperature in obesity, Am. J. Clin. Nutr. 93 (2011) 963-967.

[29] W. Bierman, The temperature of the skin surface, J. Am. Med. Assoc. 106 (1936) $1158-1162$.

[30] J.H. Choi, V. Loftness, Investigation of human body skin temperatures as a biosignal to indicate overall thermal sensations, Build. Environ. 58 (2012) 258269.
[31] K. Roback, An overview of temperature monitoring devices for early detection of diabetic foot disorders, Expert Rev. Med. Dev. 7 (2010) 711-718.

[32] H. Macias, L. Hinck, Mammary Gland Development, Wiley Interdiscip Rev Dev Biol. 1 (2012) 533-557. 